\title{
Study of Customer Experience under the Circumstances of Mobile Internet
}

\author{
Zhang Genlin ${ }^{1}$ and Xie Jie ${ }^{2}$ \\ ${ }^{1}$ School of Management Xi'an University of Science and Technology \\ ${ }^{2}$ School of Language, Literature and Law Xi'an University of Architecture and \\ Technology \\ 15339200708@189.cn
}

\begin{abstract}
These years, mobile internet, a new information communication technology (ICT), is developing quickly, stimulating the rise in demand for such products and services as intelligent terminals and mobile application clients, and in this way the marketing mode based on customer experience becomes popular. By using Customer Choice and Decisionmaking Theory in economics and investigating the market, this paper puts forward a Customer Experience-based Technology Adoption Model, which better explains the key influencing factors that may lead to the customers' final purchases under the circumstance of mobile internet. These factors consist of functions, entertainment, practicability, and reasonable pricing. In the end, based on the study result above, this paper points out that in mobile internet the operators should simplify the application functions and improve the entertainment so as to promote the value of customer experience and thus guide the occurrence of purchasing activities of the customers.
\end{abstract}

Keywords: Mobile Internet, Customer Experience-based Technology Adoption Model, Technology Adoption Model

\section{Literature Review}

Mobile Internet is a communication technology that can provide mobile business activities, which is able to provide wireless devices and help to complete a transaction through network transmission. The wireless communication technology of the first generation started in 1979, but was replaced soon by the second generation in early 1990s. The third generation, which can support multimedia like audio and video files, was originated from Japan in 2001. Currently, the fourth generation is at the initial stage. All these technologies, no matter how they develop, provide the basic services identical to the fixed Internet, which include Commerce, Communication and Contents (3Cs). The commerce service involves mobile banking, online ticketing, etc., the communication service involves email service and instant communication (e.g., wechat). The range of contents service is relatively wider, which involves content download, news and other instant services based on geographic location and time sensitivity.

In the field of information technology, the Technology Acceptance Model (TAM) proposed by Davis in 1989 is most applied. By using the Theory of Rational Action, this model studies the factors that influence the customer's acceptance for the information system. Initially, the purpose of raising the model is to interpret the widely accepted factors that may have effect on the role of computers played in enterprises. 
There are two determinants for this model: (1) perceived usefulness, which reflects the individual's perception for the improvement level of work performance brought by using a new computer system; (2) perceived ease of use, which reflects the individual's perception for the usability of a new computer system.

According to this model, the individual's choice of using a new information system is decided by his behavior intention, which is the result of joint influence of attitude toward using and perceived usefulness. In this process, the attitude toward using depends on perceived usefulness and perceived ease of use. The perceived usefulness is affected by perceived ease of use and external variables which in turn decide the degree of the perceived ease of use. These external variables include the designing features of the information system, user characteristics (involving cognitive structure and other personality traits), task features, the nature of development and implementation, policy influence and organization structure. Besides, these variables establish the connection between the interior factors like faith, attitude and intention and the factors such as individual difference, environmental constraints, and controllable interference.

With the wide use of TAM in the field of information technology, scientists make a lot of empirical research on perceived usefulness and perceived ease of use, both of which affect the individual behavioral intention of usage. Based on these researches, Venkatesh and Davis raised an expanded TAM, in which the social influence (voluntariness, subjective norm and impression) and the cognitive structure (applicability of work, the possibility of result argumentation, output quality and perceived ease of use) are the decisive factors of perceived usefulness and the intention of usage. After the individual used the system, his experience may increase, which will cause the influence of the subjective norm on the perceived ease of use and the intention of usage to become smaller. His behavior of usage is determined by his intention of usage, and the subjective norm, whose impact comes from someone important, shows the degree that an individual perceives whether to choose a behavior. Obviously, the above definition learns from the theory of rational behavior, which was not adopted in the initial TAM. In this expanded model, voluntariness refers to the degree that the individual using the information system perceives the non-compulsion of applying the new system, showing the possibility perceived by the information system user who is willing to use the new system. The impression, which is directly affected by subjective norm, means the degree perceived by an individual that implementing an information system changes his relative status in a social environment. Experience refers to the individual's cognition to the new information system after using it for a period of time. The applicability of work refers to the degree perceived by an individual that the objective system is applied to his work. The output quality indicates how much the information system matches the work target after the system is used in the practical work. The possibility of result argumentation refers to the degree that the effect of using the new information system can be precisely evaluated.

All the above studies focus on system and, based on the influence of the system on work and system users, confirm the final possibility of adopting the technology. With the development of mobile Internet technology, the customer experience has become the key that decides whether new applications and services can be accepted by the customers. This study attempts to build a Customer Experience-based Technology Adoption Model, which may be a beneficial guide for practice.

\section{Model Building and Hypotheses}

Based on the customer experience, this paper built a Technology Acceptance Model, as illustrated in chart 1. Through some variables and characteristics reflecting customer experience, this model attempts to explain the individual customer's intention for the new 
technologies and services under the circumstances of mobile internet, and eventually to complete the purchase behavior.

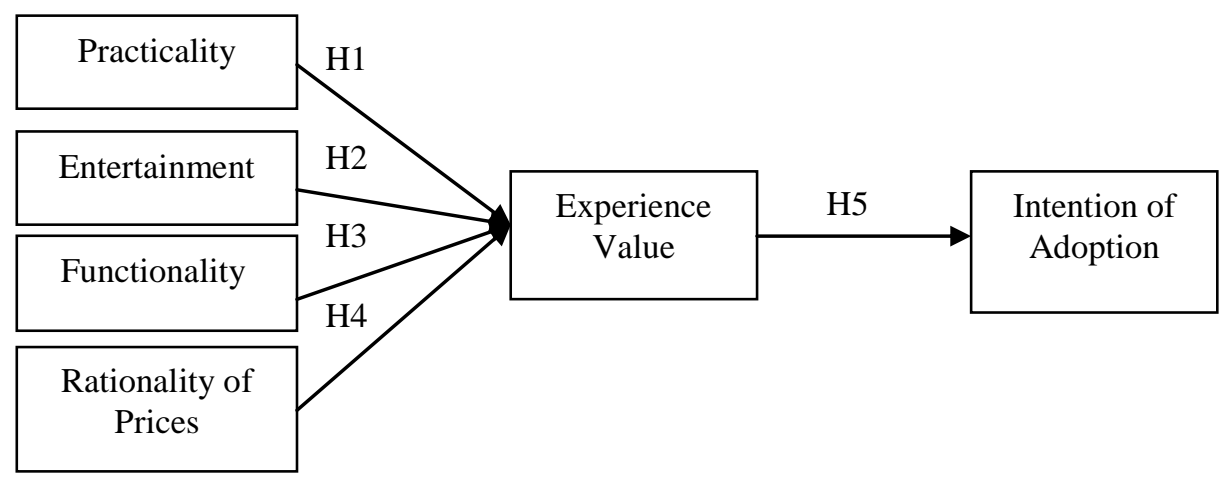

\section{Chart 1. Technology Acceptance Model Based on Customer Experience}

The cognitive development theory divided people's motivations into intrinsic motivation and extrinsic motivation both of which will influence the experience value and will further influence the intention of adoption. The experience value consists of perception and emotion. The behavior of purchasing products and services is the decision that the customers make according to the utility and enjoyment they get. Therefore this model defined anther two factors, practicality and entertainment.

Lots of research showed that the functionality and the rationality of prices are two important factors that can have impact on the individual's decision on the new technologies, so this model took them into consideration.

The specific definition of these factors are listed in Table 1.

Table 1. Definitions of the Variables

\begin{tabular}{|c|c|c|}
\hline No. & Variables & Definitions \\
\hline 1 & Practicality & $\begin{array}{l}\text { The total value that an individual perceives by using new } \\
\text { technologies and services }\end{array}$ \\
\hline 2 & Entertainment & $\begin{array}{l}\text { The emotional pleasure that an individual enjoys when using } \\
\text { new applications and services }\end{array}$ \\
\hline 3 & Functionality & $\begin{array}{l}\text { The obstacles that an individual feel when meeting the } \\
\text { complicated functions brought by new applications and services }\end{array}$ \\
\hline 4 & $\begin{array}{l}\text { Rationality of } \\
\text { prices }\end{array}$ & $\begin{array}{l}\text { The relative value of the new applications and services that an } \\
\text { individual perceives according to his own experience }\end{array}$ \\
\hline 5 & Experience Value & $\begin{array}{l}\text { The value judgment that an individual makes after integrating all } \\
\text { the intrinsic feelings and extrinsic influential factors }\end{array}$ \\
\hline 6 & $\begin{array}{l}\text { Intention of } \\
\text { Adoption }\end{array}$ & $\begin{array}{l}\text { The intention of using the new applications and services that an } \\
\text { individual produces after judging the experience value }\end{array}$ \\
\hline
\end{tabular}

Based on the above definitions, some hypotheses are put forward:

H1: The practicality shows a positive correlation with experience value.

$\mathrm{H} 2$ : The entertainment has a positive correlation with experience value. 
H3: The functionality has a negative correlation with experience value.

$\mathrm{H} 4$ : The rationality of prices shows a negative correlation with experience value.

H5: The experience value has a positive correlation with the intention of adoption.

\section{Research Methods and Result Discussion}

In order to verify the new model, this study adopted standardized psychological tests [9], in which all the measurements applied Likert 7 Grade Scale. In the questionnaire, there are three to five questions for each variable. The questionnaire survey was conducted in some colleges and 162 college students and 57 post graduates took part in the survey. In the end, 207 questionnaires were screened. The result of the survey shows that among the three functions provided by the mobile internet, the communication service is most frequently used, followed by the services of content and business. The statistical Average Values and Standard Deviations are shown in Table 2.

Table 2. Statistical Results of Variable Reliability

\begin{tabular}{ccccc}
\hline No. & Variable & Reliability & Average Value & Standard Deviation \\
\hline 1 & Practicality & 0.87 & 4.27 & 1.02 \\
2 & Entertainment & 0.90 & 4.33 & 1.11 \\
3 & Functionality & 0.83 & 4.61 & 1.05 \\
4 & Rationality of & 0.82 & 4.55 & 1.03 \\
& Prices & & 4.43 & 1.22 \\
5 & Experience & 0.85 & & \\
\hline
\end{tabular}

Pearson Correlation Analysis was applied to calculate the correlation among the variables (see Chart 2):

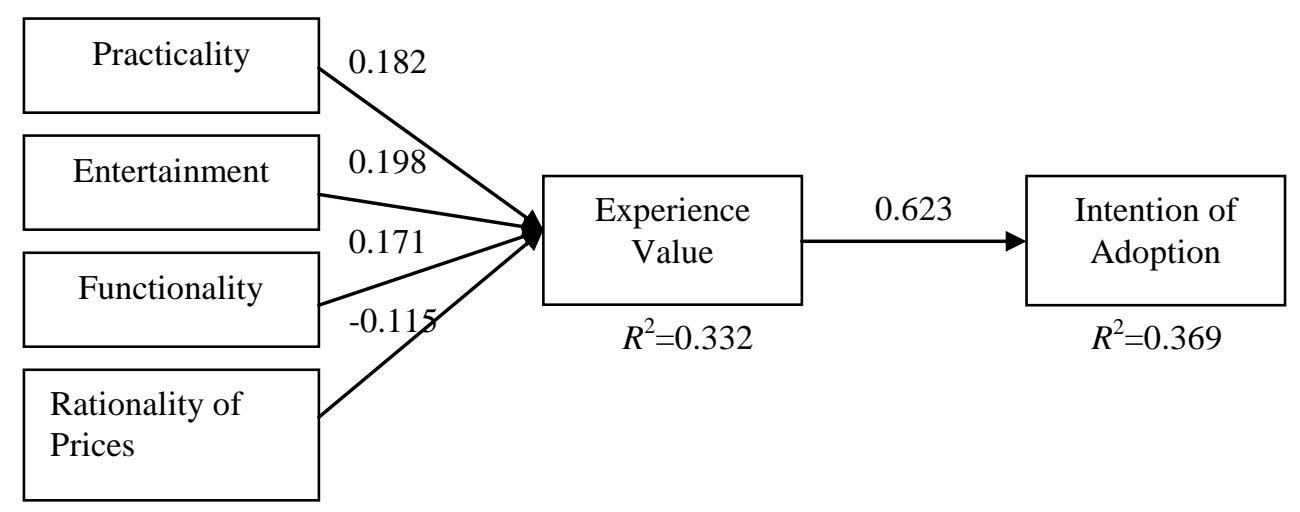

\section{Chart 2. Hypotheses Verification of the Model}

\section{Conclusion and the Issues Needing Further Research}

The above discussion indicates that the results of empirical data analysis actually support the Customer Experience-based Technology Adoption Model under the circumstance of mobile internet. In addition, the five hypotheses raised by this study are supported as well. 
From the verification result, it's obvious that there is a strong correlation between the experience value and the intention of adoption, namely, the experience value directly decides whether the customers will purchase a certain application and service. Among the four decisive factors that may affect the experience value, the correlation coefficient of entertainment is relatively high, which means that, among various applications supplied by the mobile terminal, entertainment plays a crucial role in the era of mobile internet. Next important factor is practicality, which means that, for the majority of customers, whatever applications and services are provided certain practical value is what can interest them. In contrast, the correlation of functionality is relatively weak, which indicates that for the objects in this survey the degree of difficulty of the functions will not have an evident impact on the experience value of the applications and services. There are two reasons for it. One is that the objects of this survey are mainly college students and they are good at operating most electric products; another is that the application and service providers are working on designing accessible applications, that is the new applications and services are similar to the old ones or are easy to be popularized. The price is the only factor that shows negative correlation, but its impact is relatively low, which explains that fact that most college students are not sensitive to prices and they care more about the practical value and entertainment brought by applications and services.

Based on the above analysis, the practical values and entertainment has to be designed as the major experiencing content. At the same time, the functions have to be accessible and the prices can be the last influential factor being considered.

The objects of this survey are college students. They are receiving higher education and the dormitory life helps them to learn from each other the new applications and services. In the next step, the research can expand the range of objects to learn the consumers' acceptable degree for the new technologies in the customer experience setting when the customers come from different regions and accept different levels of education.

\section{References}

[1]. K. Siau, E. Lim and Z. Shen, "Mobile Commerce, promises, challenges, and research agenda", Journal of Database Management, vol. 12, no. 3, (2001) July-September.

[2]. F. Davis, "Perceived usefulness, perceived ease of use, and user acceptance of information technology", MIS Quarte, vol. 13, no. 3, (1989), pp. 319-341.

[3]. V. Venkatesh, F. D. Davis, "A theoretical extension of the technology acceptance model", four longitudinal field studies, Management Science, vol. 46, (2000), pp. 86-205.

[4]. V. Venkatesh, G. M. Morris, G. B. Davis, et al, "User acceptance of information technology", Toward a unified view, MIS Quarterly, vol. 27, no. 3, (2003), pp. 125-478.

[5]. G.C. Moore and I. Benbasat, "Development of an instrument to measure the perceptions of adopting an information technology innovation", Information Systems Research, vol. 2, no. 3, (1991) September.

[6]. B.J. Babin, W.R. Darden and M. Griffin, "Work and/or fun measuring hedonic and utilitarian shopping value", Journal of Consumer Research vol. 20, (1994) March.

[7]. A. P. Vrechopoulos, I. D. Constantiou, N. Mylonopoulos and I. Sideris, "Critical success factors for accelerating Mobile Commerce diffusion in Europe", 15th Bled Electronic Commerce Conference, e-Reality, Constructing the e-Economy Bled, Slovenia, (2002), June 17-19.

[8]. R. P. Bagozzi and L. W. Phillips, "Representing and testing organizational theories", a holistic construal, Administrative Science Quarterly, vol. 27, no. 3, (1982) September. 


\section{Authors}

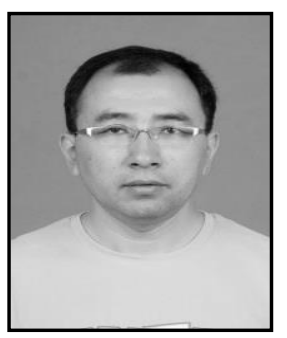

Zhang Genlin, received Ph.D. in management in 2006 and now works in School of Management Xi'an University of Science and Technology, whose main areas of research involve science of management, human resource management etc.

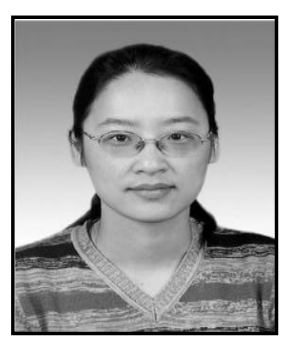

Xie Jie, received the master of Business Administration degree in 2012 and now works in School of Language, Literature and Law Xi'an University of Architecture and Technology. 